\title{
AS MICROEMPRESAS NO BRASIL: UMA INTERPRETAÇAO DO CENSO DE 1985
}

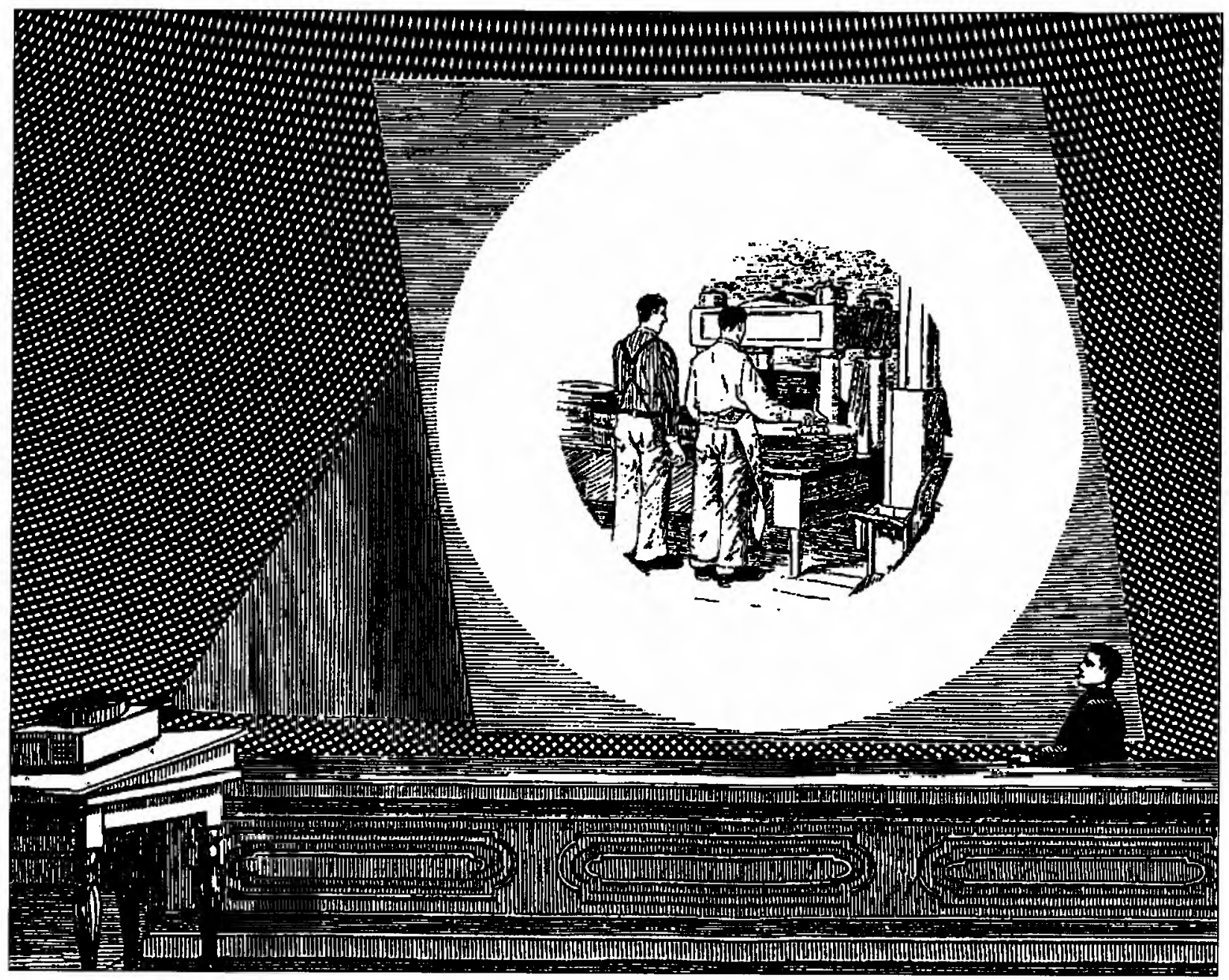

\section{- José Newton Cabral Carpintéro \\ - Maria Carolina A.F. de Souza \\ - Miguel Juan Bacic \\ Professores do Instituto de Economia da UNICAMP.}

RESUMO Este trabalho procura dar uma interpretação dos dados do Censo das Microempresas (empre- sas com faturamento menor que US\$40.000 em 1985), recentemente publicado. São destacados alguns aspectos relevantes deste estrato de empresas no país, como características, desempenho, diferenças entre classes de atividade e estratos de tamanho. Procura-se, ainda, caracterizar aquela que seria a microempresa média no Brasil.

PALAVRAS-CHAVE: Microempresas, desempenho, classe de atividade, microempresa média. 


\section{MICROEMPRESAS: CARACTERÍSTICAS GERAIS}

A publicação pioneira de um volume dos Censos Econômicos (1985) voltada exclusivamente para as microempresas $(\mathrm{ME})^{1}$ oferece oportunidades para uma reflexão sobre o desempenho e lugar ocupado por essas unidades na atividade econômica.

De início, convém explicitar que a definição incorporada pelo Censo é a do Estatuto da Microempresa- empresas com receita bruta anual menor ou igual a 10.000 ORTNs, valores referentes a janeiro do ano-base, $\mathrm{Cr} \$ 245$ milhões em $1985^{2}$. Este é o quesito básico que delimitou o universo de empresas a ser pesquisado e, por decorrência, o número total de microempresas, divulgado pelo Censo. ${ }^{3}$

A partir desse corte, chegou-se a um número de 1.007.833 microempresas em operação em 1985, empregando 2.736 .770 pessoas e gerando receitas de Cr $\$ 75$ bilhões. Tais valores correspondem, respectivamente, a $77,1 \%, 20 \%$ e $3 \%$ do valor desses itens para o total de empresas englobadas pelos Censos Econômicos, 1985. ${ }^{4}$ A observação dos da- dos agrupados nos quadros 1, 2, e 3 permite evidenciar alguns pontos sobre a distribuição das microempresas por regiões e classes de atividade econômica de forma a melhor caracterizá-las.

A região Sudeste responde por praticamente $50 \%$ dos totais apurados para o conjunto de microempresas, seja em termos de número de empresas e pessoal ocupado, seja em termos de receitas. Agregando-se os percentuais das regiões Nordeste e Sul, chega-se a $90 \%$ desse conjunto. A importância da região Sudeste é igualmente acen-

1. FUNDAÇÃO Instituto Brasileiro de Geografia e Estatística (IBGE). Censos Econômicos - 1985 Microempresas, Rio de Janeiro, IBGE, 1989.

2. Considerando o dólar médio de 1985 (Cr\$ 6.205), um faturamento anual de Cr\$ 245 milhões em 1985 correspondia a US\$39.500.

3. O número total de microempresas expressa o número de empresas pesquisadas, e em operação em 1985, com receita menor ou igual a Cr $\$ 245$ milhões anuais, excluindo-se aquelas que, por atuarem em mais de um endereço, responderam o questionário completo.

4. IBGE. Op. cit., p. XV.

\section{Quadro 1}

\section{Distribuição Percentual de Variáveis Selecionadas para Microempresas, segundo regiões e classes de atividade econômica — Brasil 1985 (*)}

\begin{tabular}{|c|c|c|c|c|c|c|c|c|}
\hline \multirow[t]{2}{*}{ Regiōes } & \multicolumn{2}{|c|}{$\mathrm{N}^{2}$ Empresas } & \multicolumn{2}{|c|}{$\begin{array}{c}\text { Pessoal Ocupado } \\
\text { em } 31 / 12 / 85\end{array}$} & \multicolumn{2}{|l|}{ Receitas } & \multicolumn{2}{|c|}{$\begin{array}{l}\text { Despesas e } \\
\text { Custos }\end{array}$} \\
\hline & V.A. & $\%$ & V.A. & $\%$ & V.A. & $\%$ & V.A. & $\%$ \\
\hline Brasil & 1007833 & 100.0 & 2736770 & 100.0 & 75304580219 & 100.0 & 59448479377 & 100.0 \\
\hline Norte & 45035 & 4.5 & 130645 & 4.8 & 4350282737 & 5.8 & 3386972368 & 5.7 \\
\hline Nordeste & 219069 & 21.7 & 613568 & 22.4 & 16119017499 & 21.4 & 13106576159 & 22.0 \\
\hline Sudeste & 490404 & 48.7 & 1327092 & 48.5 & 36306172957 & 48.2 & 28809577609 & 48.5 \\
\hline Sul & 190775 & 18.9 & 495884 & 18.1 & 13898365055 & 18.5 & 10546957369 & 17.8 \\
\hline Centro-Oeste & 62550 & 6.2 & 169581 & 6.2 & 4630741971 & 6.1 & 3598395872 & 6.0 \\
\hline \multicolumn{9}{|l|}{ Atividades } \\
\hline Brasil & 1007833 & 100.0 & 2736770 & 100.0 & 75304580219 & 100.0 & 59448479377 & 100.0 \\
\hline Indústria & 111620 & 11.1 & 454712 & 16.6 & 9159278479 & 12.2 & 7041078209 & 11.8 \\
\hline Comércio & 485571 & 48.2 & 1105205 & 40.4 & 39312431162 & 52.2 & 31735902433 & 53.4 \\
\hline Serviços & 397200 & 39.4 & 1116762 & 40.8 & 25325083476 & 33.6 & 19519185745 & 32.8 \\
\hline Construção & 6255 & 0.6 & 33676 & 1.2 & 654314060 & 0.9 & 524950246 & 0.9 \\
\hline Transportes & 7187 & 0.7 & 26415 & 1.0 & 853472772 & 1.1 & 627362744 & 1.0 \\
\hline
\end{tabular}

(*) Fonte: IBGE - Censos Econômicos 1985 - Microempresas. 


\section{Quadro 2}

Distribuição do número de microempresas por regiões e classes de atividade econômica (*)

\begin{tabular}{|c|c|c|c|c|c|c|c|c|c|c|c|c|c|c|c|c|c|c|}
\hline \multirow{2}{*}{$\begin{array}{l}\text { Regiōes } \\
\text { Atividades }\end{array}$} & \multicolumn{3}{|c|}{ Brasil } & \multicolumn{3}{|c|}{ Norte } & \multicolumn{3}{|c|}{ Nordeste } & \multicolumn{3}{|c|}{ Sudeste } & \multicolumn{3}{|c|}{ Sul } & \multicolumn{3}{|c|}{ Centro-Oeste } \\
\hline & $\%$ & V.A. & $\%$ & $\%$ & V.A. & $\%$ & $\%$ & V.A. & $\%$ & $\%$ & V.A. & $\%$ & $\%$ & V.A. & $\%$ & $\%$ & V.A. & $\%$ \\
\hline Indústria & 100 & 111620 & 11.1 & 4.4 & 4960 & 11.0 & 26.1 & 29054 & 23.3 & 40.5 & 45218 & 9.2 & 22.1 & 24625 & 12.9 & 6.9 & 7763 & 12.4 \\
\hline Comércio & 100 & 485571 & 48.2 & 5.2 & 25159 & 55.9 & 23.8 & 115400 & 52.7 & 46.3 & 225080 & 45.9 & 18.5 & 89595 & 47.0 & 6.2 & 30337 & 48.5 \\
\hline Serviços & 100 & 397200 & 39.4 & 3.7 & 14695 & 32.6 & 18.5 & 73340 & 33.5 & 53.7 & 213165 & 43.5 & 18.1 & 71927 & 37.7 & 6.0 & 24073 & 38.5 \\
\hline Construção & 100 & 6255 & 0.6 & 1.3 & 81 & 0.2 & 8.3 & 515 & 0.2 & 55.0 & 3442 & 0.7 & 32.3 & 2033 & 1.0 & 3.1 & 194 & 0.3 \\
\hline Transportes & 100 & 7187 & 0.7 & 1.9 & 140 & 0.3 & 10.6 & 760 & 0.3 & 48.8 & 3499 & 0.7 & 36.2 & 2605 & 1.4 & 2.5 & 183 & 0.3 \\
\hline Total & 100 & 1007833 & 100 & 4.5 & 45039 & 100 & 21.7 & 219069 & 100 & 48.7 & 490404 & 100 & 18.9 & 190775 & 100 & 6.2 & 62550 & 100 \\
\hline
\end{tabular}

(") Fonte: IBGE, op. cit., p. XVII.

\section{Quadro 3}

Distribuição Percentual de Variáveis Selecionadas para Alguns Ramos da Indústria e Áreas do Comércio e Serviços $\left(^{*}\right)$

\begin{tabular}{|lcccc|}
\hline & $\begin{array}{c}\text { No de } \\
\text { Empresas }\end{array}$ & $\begin{array}{c}\text { Pessoal } \\
\text { Ocupado }\end{array}$ & Receitas & $\begin{array}{c}\text { Despesas } \\
\text { E }\end{array}$ \\
& $\%$ & $\%$ & $\%$ & $\%$ \\
\hline Indústria & 100 & 100 & 100 & 100 \\
Prod. Alimentares & 21.1 & 20.0 & 24.0 & 24.6 \\
Transf. de Minerais & 20.2 & 22.1 & 14.3 & 13.9 \\
não-metálicos & & & & \\
Vestuário, calçados & 10.8 & 11.4 & 11.5 & 11.5 \\
e artefatos de tecidos & 10.3 & 10.7 & 10.1 & 10.1 \\
Madeira & 10.0 & 8.5 & 10.3 & 10.5 \\
Metalurgia & 72.4 & 72.7 & 70.2 & 70.4 \\
Subtotal & 100 & 100 & 100 & 100 \\
Comércio & 49.2 & 43.8 & 45.8 & 46.2 \\
Prod. Al. e Bebidas e Fumo & 19.7 & 20.0 & 18.8 & 18.7 \\
Tecidos & 68.9 & 63.8 & 64.6 & 64.9 \\
Subtotal & 100 & 100 & 100 & 100 \\
Serviços & 48.0 & 40.6 & 48.2 & 50.4 \\
Serv. de Alimentação & 23.3 & 22.9 & 20.0 & 19.1 \\
Serv. de Rep. e Manutenção & 71.3 & 63.5 & 68.2 & 69.5 \\
Subtotal & & & & \\
\hline
\end{tabular}

(") Fonte: IBGE: Censos Econômicos de 1985 - Microempresas.

tuada no que se refere à distribuição das atividades econômicas por região. Assim, em relação ao número total de microempresas do comércio, serviços e indústria, tem-se que $46,3 \%, 53,7 \%$ e $40,5 \%$, respectivamente, se concentram na região Sudeste, que por sua vez apresenta uma concentração de grandes centros urbanos. Evidencia-se, assim, que as ME seguem a tendência geral de buscar capitalizar os benefícios oferecidos pela infra-estrutura desses centros urbanos.

Em termos da distribuição por atividade, sobressai a participação das categorias comércio e serviços $(87,6 \%$ do total de empresas). As microempresas comerciais representam 48,2\%, 
destacando-se, dentro deste total, o pequeno comércio varejista de produtos alimentares, bebidas e fumo. A participação das empresas de serviços é de $39,4 \%$, sendo que, nesse total, os serviços relacionados à alimentação também aparecem com participação significativa. As microempresas industriais representam $11,1 \%$ e novamente aqui $o$ item produtos alimentares aparece em percentual relevante (ver quadro 3 ).

Considerando-se globalmente as microempresas comerciais, industriais e de serviços ligadas à alimentação, chega-se a aproximadamente $45 \%$ do número total de empresas e $37,5 \%$ do pessoal total ocupado pelo conjunto das microempresas. Esses dados representam $35 \%$ do número total de empresas levantadas pelos Censos Econômicos1985, mas, do ponto de vista da contribuição para o emprego, representam apenas $7,5 \%$ do pessoal ocupado. Esses percentuais não são tão surpreendentes tendo-se presente quais são concretamente essas microempresas - pequenos armazéns, bares, restaurantes etc. - e associando-as a fatores tais como baixa renda, desemprego, subemprego, característicos da realidade brasileira. Nessa perspectiva, sua proliferação e sobrevivência podem, em boa parte, ser justificadas pelo fato de apresentarem "uma certa funcionalidade" enquanto forma alternativa de consumo de produtos básicos de consumo para boa parte da população (compras fiado, cadernetas ...).

Dado que as necessidades básicas de consumo vão além do item alimentação, tem-se nessa "funcionalidade" um fator explicativo para o "tempo de vida" das microempresas: do total de empresas que declararam o ano de fundação, $23,5 \%$ foram fundadas antes de 1975 e $18,2 \%$ entre 1975 e 1979 , ou seja $41,7 \%$ haviam, em 1985 , superado o chamado período de "consolidação" da empresa (5 anos), conforme fica claro no quadro 4.

\section{MICROEMPRESAS: INDICADORES SELECIONADOS}

Considerando-se que a definição de ME no Censo envolveu fundamentalmente o critério de receita, a estratificação a partir do número de pessoas ocupadas mostra-se útil no sentido de melhor compor o perfil desse segmento de empresas (ver quadro 5).

Observa-se que no Brasil $(89,6 \%)$ e particularmente para as ME do Comércio $(95,2 \%)$ e de Serviços $(88,5 \%)$, a categoria Microempresa englo-
Quadro 4

Ano de Fundação das Microempresas - Censos Econômicos $85\left(^{*}\right)$

\begin{tabular}{|lrr|} 
Ano de Fundação & \multicolumn{2}{c}{ Número } \\
& de Empresas (**) \\
& VA & \% \\
Antes de 1975 & 198.000 & 23,6 \\
1975 a 1979 & 153.322 & 18,2 \\
1980 & 50.460 & 6,0 \\
1981 & 52.311 & 6,2 \\
1982 & 65.819 & 7,8 \\
1983 & 84.893 & 10,1 \\
1984 & 104.211 & 12,3 \\
1985 & 132.951 & 15,8
\end{tabular}

(*) Fonte: IBGE, op. cit., p. 152.

${ }^{* *}$ Os percentuais referem-se ao número de empresas que declararam ano de fundação (841.967) e não ao total de microempresas do Censo (1.007.833).

ba essencialmente empresas que ocupam até 4 pessoas (incluindo os proprietários). É, portanto, sobre os dados relativos a esse estrato que deve recair a ênfase, seja quando se trata de analisar sua dinâmica - comportamento, desempenho e participação nos resultados agregados dos setores em que se inserem - seja nas discussões referidas à formulação de medidas de apoio que as contemplem.

Por outro lado, se este tamanho (até 4 pessoas ocupadas) é predominante nas ME comerciais e de serviços, nas ME industriais a participação das unidades que ocupam entre 5 a 9 pessoas é expressiva, representando $24 \%$ dos estabelecimentos, e mais de $36 \%$ do pessoal ocupado e das receitas geradas pelas ME industriais. Também nas atividades de transportes e de construção, este estrato tem importância considerável. Em especial, na última (ME-construção) o estrato de empresas que ocupam entre 10 e 19 pessoas é ainda importante, representando $24 \%$ do P.O. e $15 \%$ das receitas geradas.

Para as ME do Brasil como um todo, independentemente de classe de atividade, os custos totais representam $79,1 \%$ da receita gerada. Nota-se que para os dados agregados, tanto os "salários + retiradas" quanto os lucros representam cerca de $20 \%$ daquelas receitas. Porém, essa participação praticamente igual entre lucros e salários + retiradas não se dá efetivamente em nenhuma das classes de atividade.

Ao se analisarem as $M E$, em cada classe de 


\begin{tabular}{|c|c|c|c|c|c|c|c|c|c|c|c|c|c|c|c|c|c|c|}
\hline \multirow[b]{2}{*}{$\begin{array}{l}\text { Estrato de } \\
\text { Tamanho } \\
\text { (NN Pessoas) }\end{array}$} & \multicolumn{3}{|c|}{ Total } & \multicolumn{3}{|c|}{ Indústria } & \multicolumn{3}{|c|}{ Comércio } & \multicolumn{4}{|c|}{ Serviços } & \multicolumn{2}{|c|}{ Transportes } & \multicolumn{3}{|c|}{ Construção } \\
\hline & NE & PO & $R$ & NE & PO & $R$ & NE & $\mathrm{PO}$ & R & NE & $\mathrm{PO}$ & $\mathbf{R}$ & NE & PO & $R$ & NE & $\mathrm{PO}$ & $\mathrm{R}$ \\
\hline 1 & 23.6 & 9.0 & 15.3 & 9.7 & 2.5 & 4.2 & 28.5 & 12.9 & 19.1 & 21.8 & 8.1 & 13.8 & 14.1 & 4.0 & 10.8 & 10.6 & 2.2 & 5.8 \\
\hline 2 & 39.7 & 30.3 & 34.3 & 25.1 & 12.8 & 15.7 & 43.5 & 39.4 & 40.6 & 39.7 & 29.3 & 32.2 & 30.3 & 17.3 & 25.3 & 21.7 & 8.9 & 15.6 \\
\hline 3 & 18.1 & 20.7 & 20.7 & 21.9 & 16.8 & 19.1 & 17.0 & 23.1 & 21.6 & 18.3 & 20.2 & 20.1 & 22.3 & 18.2 & 21.4 & 17.4 & 10.7 & 15.3 \\
\hline 4 & 8.3 & 12.6 & 11.5 & 14.9 & 15.2 & 16.6 & 6.3 & 11.5 & 9.9 & 8.7 & 12.8 & 12.0 & 12.3 & 14.1 & 13.4 & 13.6 & 11.1 & 14.1 \\
\hline $\begin{array}{l}\text { Subtotal } \\
1-4\end{array}$ & 89.6 & 72.6 & 81.9 & 71.5 & 47.3 & 55.7 & 95.2 & 86.8 & 91.2 & 88.5 & 70.3 & 78.1 & 78.0 & 53.5 & 71.0 & 63.3 & 32.9 & 50.9 \\
\hline 5 a 9 & 9.1 & 21.0 & 15.5 & 24.2 & 38.3 & 36.2 & 4.6 & 11.9 & 8.4 & 10.0 & 22.4 & 18.2 & 18.9 & 33.3 & 24.8 & 25.9 & 33.6 & 31.5 \\
\hline $10 a 19$ & 1.1 & 5.3 & 2.4 & 3.9 & 12.0 & 7.4 & 0.2 & 1.1 & 0.4 & 1.4 & 6.1 & 3.4 & 2.7 & 9.6 & 4.1 & 9.2 & 24.0 & 14.6 \\
\hline$+\operatorname{de} 20$ & 0.1 & 1.1 & 0.7 & 0.4 & 2.4 & 0.8 & 0.0 & 0.2 & 0.0 & 0.1 & 1.2 & 0.3 & 0.4 & 3.6 & 0.6 & 1.7 & 9.5 & 3.0 \\
\hline
\end{tabular}

Fonte: Censo Microempresas 1985.

$\mathrm{NE}=$ Número de estabelecimentos.

$\mathrm{PO}=$ Pessoal ocupado.

$R=$ Receitas totais.

atividade percebem-se distintas distribuições daquilo que poderia ser chamado "valor adicionado". Assim, encontra-se desde uma participação de 32,1\% (para sal. + ret.) e 19,6\% (para lucros) nas ME-construção até $14,8 \%$ (sal. + ret.) e $18,9 \%$ (lucro) nas ME-comerciais. Essas diferenças não chegam a ser surpreendentes, dadas as características de cada atividade. Dessa forma, uma análise por estrato de tamanho torna-se mais esclarecedora.

Para as ME como um todo, já se nota a quase igualação dos custos com a receita a partir do estrato com mais de 10 pessoas empregadas, chegando a atingir $99,7 \%$ nas ME com 20 ou mais pessoas ocupadas. Estas unidades, como será visto mais adiante, não são propriamente ME e sua inclusão no Censo deve ser qualificada.

Nas ME industriais e de serviços, essa perda da eficiência econômica com o aumento do porte, medida pela relação custo/receita, é acentuada, indo de $66,8 \%$, no primeiro estrato. de tamanho (uma pessoa ocupada), a, aproximadamente, $73 \%$ (entre 2 e 3 ), até atingir cerca de $95 \%$ nas empresas com mais de 20 pessoas.

Essa perda não é tão acentuada no caso das ME comerciais, quanto a que ocorre nas ME de transportes e de construção, chegando as empresas com mais de 20 pessoas ocupadas a terem margens de lucro negativas.

Ao se tomar o item salários e retiradas, pode-se perceber que sua participação nas receitas avança de cerca de $18 \%$, nas unidades com até 4 pessoas ocupadas, para cerca de $41 \%$ (entre 10 e 19 pessoas ocupadas) até atingir 55\% naquelas com 20 e mais pessoas ocupadas. Essa participação é mais acentuada nas ME comerciais, de transportes e construção.

Esses dados a respeito do pior desempenho das ME de maior porte são corroborados pela análise dos indicadores a seguir:

Tomando-se valores gerados por pessoa ocupada tem-se inicialmente que as ME-comerciais e de transportes geram os maiores valores, bem acima das demais atividades. As de transportes, além de pagar os maiores "salários + retiradas", geram os maiores lucros por pessoa ocupada.

À medida que aumenta o tamanho dessas ME, percebe-se que, sem haver redução sensível dos salários + retiradas por pessoa ocupada por estrato (até a faixa de 10-19 pessoas ocupadas), reduzse no geral o lucro por P.O. a partir do estrato de 5 a 9, tornando-se quase inexistente nas ME com 20 e mais pessoas ocupadas, principalmente nas ME de transporte e de construção.

Percebe-se que essas empresas maiores (estratos de 10 a 19 e especialmente com 20 e mais pessoas ocupadas), consideradas pelo Censo como microempresas, são realmente empresas pequenas (e não $\mathrm{ME}$ ) de baixo faturamento que não atingiram o limite máximo de vendas anuais que caracteriza, do ponto de vista jurídico, uma ME (10.000 ORTN's). Esse baixo faturamento (em proporção a seu porte) justifica o deficiente comportamento dos indicadores vistos nos quadros 6 e 7. 
Quadro 6:

Indicadores Selecionados - por Classe de Atividade e Estrato de Tamanho

(Em Percentuais)

\begin{tabular}{|c|c|c|c|c|c|c|c|c|c|c|c|c|c|c|c|c|c|c|}
\hline \multirow{3}{*}{$\begin{array}{l}\text { Estrato } \\
\text { (Pessoas) }\end{array}$} & \multirow{3}{*}{$\frac{\mathrm{C}}{\mathrm{R}}$} & \multirow{3}{*}{$\frac{\text { Geral }}{\frac{S+R}{R}}$} & \multirow{3}{*}{$\frac{\mathrm{L}}{\mathbf{R}}$} & \multirow{3}{*}{$\frac{\mathrm{C}}{\mathrm{R}}$} & \multicolumn{2}{|c|}{ ndústria } & \multicolumn{3}{|c|}{ Comércio } & \multicolumn{3}{|c|}{ Serviços } & \multicolumn{3}{|c|}{ Transportes } & \multicolumn{3}{|c|}{ Construção } \\
\hline & & & & & $\mathrm{S}+\mathrm{R}$ & $\mathrm{L}$ & C & $S+R$ & L & $c$ & $S+R$ & $L$ & $c$ & $S+R$ & L & C & $S+R$ & $\mathrm{~L}$ \\
\hline & & & & & $\mathrm{R}$ & $\mathbf{R}$ & $\mathrm{R}$ & $\mathrm{R}$ & $\mathrm{R}$ & $\mathrm{R}$ & $\mathbf{R}$ & $\mathrm{R}$ & $\mathrm{R}$ & $\mathbf{R}$ & $\mathrm{R}$ & R & $R$ & $R$ \\
\hline Total & 79.1 & 20.4 & 20.8 & 77.1 & 25.9 & 22.9 & 81.1 & 14.8 & 18.9 & 77.1 & 26.9 & 22.9 & 73.5 & 21.1 & 26.5 & 80.4 & 32.1 & 19.6 \\
\hline 1 & 77.0 & 13.4 & 23.0 & 66.8 & 16.9 & 33.2 & 78.9 & 11.7 & 21.1 & 74.5 & 16.7 & 25.5 & 63.8 & 11.1 & 36.1 & 61.2 & 16.8 & 38.8 \\
\hline 2 & 78.5 & 17.7 & 21.5 & 72.5 & 21.9 & 27.5 & 80.9 & 14.1 & 19.0 & 75.1 & 24.2 & 24.9 & 68.1 & 15.7 & 31.8 & 68.5 & 22.1 & 31.5 \\
\hline 3 & 78.6 & 20.2 & 21.4 & 74.5 & 23.2 & 25.5 & 81.2 & 15.2 & 18.8 & 76.0 & 27.5 & 24.0 & 70.8 & 18.6 & 29.2 & 75.6 & 24.5 & 24.4 \\
\hline 4 & 79.1 & 22.7 & 20.8 & 76.3 & 24.4 & 23.7 & 81.9 & 16.7 & 18.1 & 77.3 & 29.3 & 22.6 & 75.5 & 22.5 & 24.4 & 75.6 & 28.5 & 24.4 \\
\hline \multicolumn{19}{|l|}{ Subtotal } \\
\hline $1-4$ & 78.3 & 18.2 & 21.7 & 73.9 & 22.7 & 26.1 & 80.7 & 14.1 & 19.3 & 75.5 & 24.5 & 24.4 & 69.7 & 17.2 & 30.3 & 71.8 & 24.0 & 28.2 \\
\hline 5 a 9 & 81.7 & 28.3 & 18.3 & 79.9 & 27.8 & 20.1 & 84.4 & 20.6 & 15.6 & 81.1 & 33.8 & 18.9 & 80.6 & 28.4 & 19.4 & 82.9 & 34.7 & 17.0 \\
\hline 10 a 19 & 88.8 & 41.1 & 11.2 & 85.8 & 38.5 & 14.2 & 92.9 & 33.9 & 7.0 & 89.4 & 43.7 & 10.6 & 92.1 & 40.1 & 7.9 & 96.0 & 48.1 & 3.9 \\
\hline+ de 20 & 99.7 & 55.1 & 0.3 & 94.3 & 49.4 & 5.6 & 99.2 & 50.1 & 0.8 & 97.8 & 58.5 & 2.1 & 112.9 & 61.1 & -12.9 & 122.5 & 63.5 & -22.5 \\
\hline
\end{tabular}

Fonte: Censo Microempresas 1985

$\mathrm{C}=$ Custos totais.

$L=$ Lucro

$S+R=$ Salários + Retiradas

$\mathrm{R}=$ Receitas totais.

\section{Quadro 7}

Indicadores Selecionados - Microempresas - por Classe de Atividade e Estrato de Tamanho (em valores de 1985)

\begin{tabular}{|c|c|c|c|c|c|c|c|c|c|c|c|c|c|c|c|c|c|c|}
\hline \multicolumn{2}{|c|}{$\begin{array}{l}\text { Classe de Ativ. } \\
\text { Indicadores }\end{array}$} & \multicolumn{2}{|c|}{ Total } & \multicolumn{3}{|c|}{ Indústria } & \multicolumn{3}{|c|}{ Comércio } & \multicolumn{3}{|c|}{ Serviços } & \multicolumn{3}{|c|}{ Transportes } & \multicolumn{3}{|c|}{ Construçáo } \\
\hline & $\mathrm{R}$ & $S+R$ & L & $R$ & $S+R$ & L & $\mathbf{R}$ & $S+R$ & L & $R$ & $S+R$ & L & $\mathrm{R}$ & $S+R$ & L & $\mathrm{R}$ & $S+R$ & L \\
\hline $\begin{array}{l}\text { Pessoal } \\
\text { Ocupado }\end{array}$ & P.O. & P.O. & P.O. & P.O. & P.O. & P.O. & P.O. & P.O. & P.O. & P.O. & P.O. & P.O. & P.O. & P.O. & P.O. & P.O. & P.O. & P.O. \\
\hline Total & 28507 & 5825 & 5942 & 20949 & 5430 & 4799 & 36707 & 5417 & 6949 & 23499 & 6330 & 5384 & 33798 & 7123 & 8954 & 21485 & 6889 & 4219 \\
\hline 1 & 48499 & 6511 & 11160 & 35810 & 6074 & 11888 & 54307 & 6367 & 11447 & 40260 & 6717 & 10272 & 91196 & 10158 & 32968 & 57491 & 9686 & 22291 \\
\hline 2 & 32313 & 5733 & 6953 & 25756 & 5637 & 7085 & 37773 & 5311 & 7183 & 25881 & 6264 & 6455 & 49554 & 7780 & 15785 & 37746 & 8342 & 11879 \\
\hline 3 & 28582 & 5766 & 6111 & 23847 & 5525 & 6077 & 34387 & 5217 & 6453 & 25332 & 6407 & 5599 & 39921 & 7414 & 11647 & 30773 & 7530 & 7515 \\
\hline 4 & 25950 & 5887 & 5411 & 22872 & 5574 & 5429 & 31703 & 5290 & 5746 & 22116 & 6489 & 5010 & 32322 & 7271 & 7907 & 27109 & 7734 & 6623 \\
\hline \multicolumn{19}{|l|}{ Subtotal } \\
\hline $1-4$ & 32147 & 5865 & 6966 & 24677 & 5600 & 6446 & 38530 & 5440 & 7433 & 26109 & 6399 & 6383 & 44883 & 7700 & 13600 & 33190 & 7961 & 9372 \\
\hline 5 a 9 & 20963 & 5925 & 3838 & 19771 & 5499 & 3976 & 25838 & 5330 & 4039 & 19110 & 6453 & 3618 & 24687 & 7002 & 4795 & 20152 & 6990 & 3439 \\
\hline 10 a 19 & 13088 & 5378 & 1466 & 12833 & 4945 & 1821 & 14418 & 4893 & 1015 & 13019 & 5695 & 1377 & 14360 & 5765 & 1140 & 13066 & 6279 & 517 \\
\hline+ de 20 & 6087 & 3352 & 15 & 6845 & 3384 & 381 & 5049 & 2531 & 40 & 5490 & 3213 & 118 & 5423 & 3316 & $(702)$ & 6845 & 4349 & (1538) \\
\hline
\end{tabular}

Fonte: Censo Microempresas 1985.

$\mathrm{R}=$ Receitas totais.

$L=$ Lucro

$\mathrm{S}+\mathrm{R}=$ Salários + Retiradas

$R=$ Receitas totais. 


\section{A MICROEMPRESA MÉdIA}

O estudo da microempresa média (MEM) possibilita observar aspectos relevantes da estrutura de custos e de ocupação dentro da unidade. Ao trabalhar com números médios, caracteriza-se, de forma mais concreta, o que seria uma ME dentro de cada classe de atividade. Deve-se ressaltar que essa MEM não é exatamente igual à empresa representativa marshalliana. ${ }^{5}$ Porém, dada a grande concentração de ME no estrato de 1-4 pessoas ocupadas $(89,6 \%$ do total), pode-se afirmar a priori que a média não será muito influenciada pelos extremos e fornecerá um número razoavelmente representativo de uma ME para cada variável analisada.

A estrutura ocupacional dentro de cada unidade, segundo classe de atividade, aparece no quadro 8.

Nota-se a importância do trabalho dos proprietários e familiares, que representam $58 \%$ do pessoal ocupado total. Isto indica que a função desempenhada pelos proprietários é ligada diretamente à atividade produtiva, não efetuando estes, mais que em caráter marginal, tarefas administrativas. Estas não são funcionalmente separadas como em empresas de maior porte, inclusive pequenas e médias. $O$ número médio de proprietários por unidade é de 1,27 pessoas e permanece relativamente estável em todas as classes de atividade. $\mathrm{O}$ mesmo fenômeno se verifica com os familiares sem remuneração $(0,31$ por empresa). Estes, porém, mantêm uma relação diferenciada com o número de empregados por classe de atividade. Observa-se

\section{Quadro 8}

\section{Estrutura Ocupacional por M.E. Média por Classe de Atividade}

- Número de Pessoas -

\begin{tabular}{|lcccccc|}
\hline & TOTAL M.E. & IND. & COMER. & SERV. & TRANSP. & CONSTR. \\
\hline . Pessoal Ocupado & & & & & & \\
Total & 2,72 & 4,13 & 2,28 & 2,81 & 3,68 & 5,40 \\
. Proprietários & 1,27 & 1,34 & 1,24 & 1,27 & 1,48 & 1,68 \\
. Empregados & 1,15 & 2,46 & 0,69 & 1,29 & 2,08 & 3,61 \\
. Familiar sem Rem. & 0,31 & 0,33 & 0,35 & 0,26 & 0,13 & 0,11 \\
\hline
\end{tabular}

FONTE: IBGE, op. cit.

\section{Quadro 9}

\section{Emprego por ME e Classe de Atividade}

\begin{tabular}{|lccccc|}
\hline & COMÉRCIO & SERVIÇO & INDÚSTRIA & TRANSPORTE & CONSTRUÇÃO \\
\hline $\begin{array}{l}\text { Part. classe ativ. } \\
\text { no Total ME }\end{array}$ & $48,2 \%$ & $39,4 \%$ & $11,1 \%$ & $0,7 \%$ & $0,6 \%$ \\
Empregado por ME/ & $30,3 \%$ & $45,9 \%$ & $59,6 \%$ & $56,5 \%$ & $66,9 \%$ \\
\hline P.O.T. por ME & & & & & \\
\hline
\end{tabular}

FONTE: IBGE, op. cit. uma relação de 1 familiar sem remuneração para cada 2 empregados no comércio contra $1: 5$ nos serviços, que é o caso mais próximo ao anterior, e $1: 32$ na construção, que é o caso extremo.

A diferença na ocupação total, segundo classe de atividade, deve-se à variação no número de empregados. Em média, as ME empregam uma pessoa por unidade. $O$ maior número de empregados por MEM encontra-se na construção, indústria e transportes. Nas duas classes de atividade nas quais se concentra a maior quantidade de ME (comércio e serviços $86,7 \%$ do total), os empregados representam menos da metade do total de pessoas ocupadas, sendo mínima esta proporção no comércio, que é exatamente a classe mais numerosa de ME.

A importância do emprego como proporção da ocupação total é inversamente proporcional à participação de cada classe de atividade no total de ME, como se vê no quadro 9 .

5. A firma repesentativa (ou empesa típica) nos termos de Marshall "deve ser uma que tenha tido uma existência bastante longa e razoável êxito, que seja dirigida com habilidade normal e que tenha acesso normal às economias externas e internas pertencentes àquele volume global de produção, levando-se em conta a classe de artigos produzidos, as condições de comercialização e o ambiente econômico em geral. Assim, pois, uma empresa típica é, em certo sentido, uma empresa média. MARSHALL, A. Princípios de Economia. (Trad. port.) S. Paulo, Abril Cultural, Col. "Os Economistas", 1982, p. 267 (grifos nossos). 
Quadro 10

Estrutura de Custos e Receitas por Classe de Atividade e por M.E. (*) Cruzeiros Mil - 1985 - (Dólar Médio de 1985 = Cr\$ 6,205)

\begin{tabular}{|lrrrrrrr} 
& TOTAL M.E. & IND. & COMER. & SERV. & TRANSP. & CONSTR. \\
\hline Receitas c/Imp. & 78.105 & 87.181 & 85.027 & 65.807 & 122.628 & 107.268 \\
(-) Impostos s/VDA & 3.388 & 5.142 & 4.070 & 2.049 & 3.876 & 2.640 \\
(=) Receitas s/IMP. & 74.716 & 82.039 & 80.957 & 63.758 & 118.752 & 104.628 \\
(-) Desp. Operac. & 39.209 & 36.695 & 49.570 & 26.825 & 55.332 & 40.869 \\
(-) Aluguéis & 3.900 & 4.124 & 3.643 & 4.094 & 5.732 & 4.676 \\
(-) Impostos e Taxas & 1.170 & 1.466 & 1.037 & 1.236 & 1.573 & 1.827 \\
(-) PIS/FINSOCIAL & 915 & 1.056 & 913 & 849 & 1.458 & 1.386 \\
(-) Salários & 5.252 & 10.761 & 2.984 & 6.133 & 12.358 & 18.660 \\
(-) Retiradas & 10.074 & 10.551 & 9.015 & 11.103 & 12.751 & 15.240 \\
(-) Encargos Sociais & 2.667 & 4.093 & 2.142 & 2.794 & 4.869 & 6.862 \\
(=) Lucro & 11.530 & 13.294 & 11.653 & 10.726 & 24.679 & 15.108 \\
Total Custos e Despesas & 63.187 & 68.745 & 69.304 & 53.033 & 94.074 & 89.520 \\
Lucros + Retiradas & 21.603 & 23.845 & 20.668 & 21.828 & 37.429 & 30.348 \\
\hline
\end{tabular}

FONTE: IBGE, op. cit.

$\left({ }^{*}\right)$ Nota Metodológica: a abertura das contas é a máxima propiciada pelos dados do Censo. O valor médio de cada conta foi calculado dividindo o valor total pelo número de informantes do quesito. No caso dos encargos sociais, foram aplicadas as taxas encontradas nos quadros 28 a 33 do Censo sobre o valor de salários e retiradas dos quadros 16 a 21.

\section{Quadro 11}

\section{Participação no Total dos Custos e Despesas}

\begin{tabular}{|lrrrrrr|}
\hline & TOTAL M.E. & IND. & COMER. & SERV. & TRANSP. & CONSTR. \\
\hline Despesas operacionais & 62,1 & 53,4 & 71,5 & 50,6 & 58,8 & 45,6 \\
Retiradas & 15,9 & 15,3 & 13,0 & 20,9 & 13,6 & 17,0 \\
Salários & 8,3 & 15,7 & 4,3 & 11,6 & 13,1 & 20,8 \\
Outros & 13,7 & 15,6 & 11,2 & 16,9 & 14,5 & 16,6 \\
TOTAL & 100 & 100 & 100 & 100 & 100 & 100 \\
\hline
\end{tabular}

FONTE: IBGE, op. cit.

\section{Quadro 12}

MEM - Indicadores Selecionados - Participação em \% (*)

\begin{tabular}{|lrrrrrr|}
\hline & TOTAL M.E. & IND. & COMER. & SERV. & TRANSP. & CONSTR. \\
\hline Lucro/receit.c/imp. & 14,8 & 15,2 & 13,7 & $.16,0$ & 20,1 & 14,1 \\
Lucro/Rec. s/imp. & 15,4 & 16,2 & 14,4 & 16,8 & 20,8 & 14,4 \\
Lucro/custo & 18,3 & 19,3 & 16,8 & 20,2 & 26,2 & 16,9 \\
Desp. Op./Rec. s/imp. & 52,4 & 44,7 & 61,2 & 42,1 & 46,6 & 39,1 \\
Salários/Rec. s/imp. & 7,0 & 13,1 & 3,7 & 9,6 & 10,4 & 17,8 \\
Retir./Rec. s/imp. & 13,5 & 12,9 & 11,1 & 17,4 & 10,7 & 14,6 \\
Custo/Rec. s/imp. & 80,9 & 78,9 & 81,5 & 80,6 & 76,7 & 83,5 \\
Custo/Rec. s/imp. & 84,6 & 83,8 & 85,6 & 83,2 & 79,2 & 85,6 \\
Sal./Desp. e Custos & 8,3 & 15,7 & 4,3 & 11,6 & 13,1 & 20,8 \\
Ret./Desp. e Custos & 16,0 & 15,4 & 13,0 & 20,9 & 13,6 & 17,2 \\
Lucro/Salários & 219,5 & 123,5 & 390,4 & 174,9 & 199,7 & 81,0 \\
Lucro/Salários + Ret. & 75,2 & 62,4 & 97,1 & 62,2 & 98,3 & 44,6 \\
\hline
\end{tabular}

(*) A diferença existente entre os resultados aqui apresentados e os indicados na parte anterior deve-se à diferente metodologia utilizada. Os Quadros 6 e 7 foram calculados a partir dos valores totais do Censo sem ser efetuado o ajuste para o número de informantes como é realizado nesta parte. 


\section{Quadro 13 \\ Salários e Retiradas: Média Anual por Pessoa Ocupada segundo Tipo de Rendi- mento em Salário Mínimo de $1985\left(^{\star}\right)$, inclusive $13^{\circ}$ Salário}

\begin{tabular}{|lcccccc|}
\hline & TOTAL M.E. & IND. & COMER. & SERV. & TRANSP. & CONSTR. \\
\hline Salário por Empr. & 1,02 & 0,98 & 0,97 & 1,06 & 1,33 & 1,16 \\
Retirada por Propr. & 1,78 & 1,76 & 1,63 & 1,96 & 1,93 & 2,03 \\
Retir. por Prop. + & 1,43 & 1,41 & 1,27 & 1,63 & 1,77 & 1,91 \\
$\begin{array}{l}\text { Fam. s/rem. } \\
\text { Lucro + Ret. por }\end{array}$ & 3,06 & 3,20 & 2,91 & 3,20 & 5,21 & 3,80 \\
\hline Prop. + Fam. s/rem. & & & & & &
\end{tabular}

FONTE: IBGE, op. cit.

(") O salário mínimo anual total de 1985, inclusive o $13^{\circ}$ salário, é de 4.465 .000 cruzeiros o que corresponde aproximadamente a 60 dólares por mês.

Tanto o baixo número de empregados por unidade como a relação inversa entre a importância do emprego por ME na classe de atividade e a importância da classe no total das ME mostram, claramente, que essas empresas aparentam ter dificuldade estrutural em oferecer, em média, emprego a mais de uma pessoa, fora o proprietário e eventual familiar que colabora com o negócio. Essa constatação não surpreende, dada a definição do universo recenseado (empresas de baixo faturamento).

A estrutura de custos e receitas por MEM aparece no quadro 10.

Observa-se (ver quadro 11) que as despesas operacionais representam a maior parcela dos custos para todas as classes de atividade, seguindo-se retiradas e salários em ordem de importância.

Uma comparação inter-classes quanto à receita média ${ }^{6}$ e massa de lucro gerada destaca as empresas de transporte e construção como as maiores, ficando as de serviços em último lugar.

A construção de alguns indicadores, no quadro 12 , permite verificar o comportamento diferenciado da MEM por classe de atividade.

No referente à margem de lucro, destaca-se, novamente, a classe transporte $(20,1 \%)$ assumindo serviços um segundo lugar, próximo, porém, às margens das outras classes, que oscilam de 14 a $15 \%$. Os salários representam $8,3 \%$ dos custos e despesas em média, com um mínimo de $4,3 \%$ no comércio e um máximo de $20,8 \%$ na construção. Isto justifica que a relação lucro/salários, que é, em média, de $219,5 \%$, seja máxima no comércio $(390,4 \%)$ e mínima na construção $(81,0 \%)$. A menor participação dos salários no custo do comércio deve-se ao menor número de empregados por empresa dessa classe de atividade, mais que à diferença salarial, como demonstra o quadro 13.

Observa-se que o salário médio pago ao empregado é praticamente igual a um salário mínimo, o que não é surpreendente dado que a retirada média por proprietário não chega a dois salários mínimos. A soma do lucro às retiradas? não altera muito essa situação. Nesse caso, a remuneração média por proprietário situa-se em torno de três salários mínimos. Situação ainda pior é a do empregado, que beira, do ponto de vista salarial, o limiar da sua possibilidade de reprodução física.

Isso confirma diversos estudos ${ }^{8}$, nos quais as M.E. inseridas geralmente no chamado "setor in-

6. Ao expressar a receita total anual em dólares, que é de US\$ 12.587 depara-se claramente com o reduzido volume de operações dessas empresas, pouco mais de 1.000 dólares por mês.

7. A inclusão do lucro junto com as retiradas permite eliminar o efeito da possível subestimação do valor das retiradas por parte dos microempresários. Por outro lado, fornece um indicador que tende a superestimar a remuneração dos proprietários porque parte desse lucro provavelmente deverá ser destinado à manutenção do poder aquisitivo dos recursos destinados ao giro, vistas as condições de reduzido poder de negociação face a fornecedores e inclusive clientes que essas unidades apresentam.

8. Em especial, sugere-se a leitura de: ALMEIDA, A.L.O. "Subcontratação e 'Emprego Disfarçado' na Industrializacão Brasileira". In.: PPE, Rio de Janeiro, vol. 9, no 1, abril, 1979; e SOUZA, P.R.C. "Salário e Mão-deObra Excedente". In: Estudos CEBRAP 25, São Paulo, 1979. 


\section{Quadro 14}

\section{Impostos, Taxas, Contribuições ao IAPAS e FGTS em Proporção ao Lucro}

\begin{tabular}{|lcccccc|}
\hline & $\begin{array}{c}\text { TOTAL } \\
\text { M.E. }\end{array}$ & IND. & COMER. & SERV. & TRANSP. & CONSTR. \\
\hline Total/Lucro & $70,6 \%$ & $88,4 \%$ & $70,4 \%$ & $64,6 \%$ & $47,7 \%$ & $84,1 \%$ \\
\hline
\end{tabular}

FONTE; IBGE, op. cit.

Quadro 15

Pagamentos declarados de impostos e encargos

\begin{tabular}{|lrrrrrr|}
\hline & $\begin{array}{c}\text { TOTAL } \\
\text { M.E. }\end{array}$ & IND. & COMER. & SERV. & TRANSP. & CONSTR. \\
\cline { 3 - 4 } EII/TE & 48,2 & 44,2 & 49,6 & 47,3 & 51,4 & 52,5 \\
Taxa Média de Imp. das EII & 4,5 & 6,3 & 5,0 & 3,2 & 3,3 & 2,5 \\
EIES/TE & 71,7 & 67,3 & 73,6 & 70,0 & 89,2 & 91,9 \\
\hline
\end{tabular}

FONTE; IBGE, op. cit.

E.l.l.: Empresas que informaram terem pago impostos sobre vendas e serviços prestados (ICM, IPI, ISS, ISTR etc.).

T.E.: Total Microempresas.

E.I.E.S.: Empresas que informaram terem pago encargos sociais e trabalhistas (IAPAS, FGTS).

formal"9 não são assemelhadas a um investimento capitalista stricto sensu, dado que a maior preocupação do proprietário é a sua sobrevivência e não o comportamento da taxa de lucro do capital investido. As M.E., portanto, formam uma "rede de proteção" que impede que parte das pessoas que perderam o emprego ou que, dada sua baixa qualificação profissional, não encontram emprego em empresas de maior porte, batam no piso do desemprego. O nível de remuneração que essa "rede" oferece não é muito maior que aquela obtida através do seguro-desemprego.

O padrão de simples sobrevivência verificado nessas unidades torna-as muito propensas a pagarem o mínimo possível aos empregados (com o salário mínimo legal atuando como piso que impede queda maior) e a sonegarem o maior valor possível de impostos e outras contribuições ao governo e órgãos previdenciários. Esses pagamentos "ao governo"10 representam elevada proporção sobre o lucro e evidentemente qualquer ponto sonegado tem imediato e substancial efeito sobre o rendimento dos proprietários.

Sem dúvida, o Estatuto da Microempresa deve ter contribuído para que essa proporção apareça reduzida relativamente a valores passados. Porém, a baixa massa de lucro que as M.E. apre- sentam torna-as muito sensíveis a qualquer valor pago de impostos, taxas, contribuições e previdência etc. - que representam $70,6 \%$ do lucro em 1985, como se vê no quadro 14.

Alguns indicadores, extremamente grosseiros, sobre a proporção da sonegação podem ser vistos no quadro 15.

Menos da metade das M.E. informaram que pagaram algum tipo de imposto sobre vendas ou serviços prestados, com as informantes pagando uma taxa média de $4,5 \%$. Nesse caso, confundem-se dois fenômenos, o da possível sonegação impositiva e o das isenções tributárias previstas no Estatuto das Microempresas. ${ }^{11}$ No referente às

9. Recorre-se à concepção de SOUZA (op. cit., p. 89) "formas de organização que se inserem na estrutura econômica, de forma intersticial junto com as formas propriamente capitalistas, mas atuando em espaços de mercado perfeitamente delimitados que são criados, destruídos e recriados pela expansão do sistema hegemônico..."

10. Incluem-se aqui os impostos sobre vendas $e$ serviços prestados, as taxas municipais, os encargos sociais e trabalhistas IAPAS, FGTS, PIS e FINSOCIAL.

11. O nível de abrangência de isenção tributária foi definido de forma diferenciada em cada Estado e Município de Federação. 
contribuições ao IAPAS e FGTS, nota-se que quase $30 \%$ dessas empresas não informaram ter efetuado qualquer recolhimento. Uma boa parcela desses $30 \%$ pode ser justificada pela existência de $25 \%$ de empresas com uma única pessoa ocupada (o proprietário) que não estava pagando sua contribuição ao IAPAS. Porém, como não se pode supor que esse fenômeno seja "universal", fica a constatação que um apreciável número de M.E. (de 5 a 30\% do total) não declarou ter efetuado os recolhimentos devidos à Previdência Social no ano de 1985. Isso não significa que se esteja defendendo um maior rigor da fiscalização nesse segmento: sua pulverização torna muito custosa essa operação. Por outro lado, qualquer multa elevada pode ter o efeito de fechar a empresa dado o baixo rendimento médio dessas unidades. Ademais, vista a baixa participação das receitas das ME no total das receitas dos Censos Econômicos $-85(3 \%)$, os resultados serão irrisórios do ponto de vista de aumento da arrecadação.

\section{MICROEMPRESA MÉDIA A NÍVEL REGIONAL}

A análise regional permite caracterizar certos aspectos de ocupação e rendimento que ficaram obscuros no item anterior.

$\mathrm{O}$ quadro 16 mostra que as M.E. do Norte e Nordeste são as mais empregadoras por unidade, apresentando inclusive maior número de familiares sem remuneração:

A falta de melhores oportunidades de emprego leva a uma maior ocupação de não proprietários dentro das M.E. localizadas nas regiões de menor desenvolvimento econômico do país. Aparece aqui, novamente, o papel de "rede de proteção" que essas empresas desempenham frente ao desemprego potencial.
Outro fenômeno interessante é que o número de proprietários por unidade é diretamente relacionado com o desenvolvimento econômico da região. Aspectos diferenciadores quanto às classes e gêneros de atividade podem ajudar a explicar esse fenômeno. Porém, outro fator que deve ser levado em conta é que a associação de esforços para abrir e gerir uma empresa, ou seja a sociedade jurídica coletiva, caracteriza formas mais avançadas de desenvolvimento organizacional, em contraposição à empresa individual. Nesse caso, fica em aberto a questão: se haveria um paralelo entre o grau de desenvolvimento econômico regional e o grau de desenvolvimento organizacional das M.E. A quantidade de proprietários + familiares sem remuneração é semelhante em todas as regiões, oscilando entre um mínimo de 1,48 e um máximo de 1,61 pessoas. Parece que as ME do Norte e Nordeste compensam, de certa maneira, o menor número de proprietários com um aumento dos familiares sem remuneração, os quais desempenhariam o papel de "agente de confiança" da unidade.

A análise do salário e da retirada média por pessoa ocupada revela claras diferenças regionais, que podem ser vistas no quadro 17 .

Mesmo oscilando o salário por empregado em torno de um salário mínimo, existem diferenças entre as regiões. $O$ Nordeste é quem paga menores valores, ficando inclusive abaixo do mínimo. A região Norte aparenta ser a que paga valores mais altos. Neste caso, cabe lembrar que podem estar influindo razões ligadas ao custo de reprodução da força de trabalho, que é bem superior nessa região, comparativamente às outras do país.

Chama muito a atenção o comportamento diferenciado das retiradas por proprietário. A região Norte, seguida não muito de perto pelo

\section{Quadro 16}

Estrutura Ocupacional por M.E. Média - Por Região - Número de Pessoas

\begin{tabular}{|lcccccc|}
\hline & $\begin{array}{c}\text { TOTAL } \\
\text { M.E. } \\
\text { BRASIL }\end{array}$ & NORTE & NORDESTE & SUDESTE & SUL & CENTRO-OESTE \\
\hline Pessoal Ocupado Total & 2,72 & 2,91 & 2,81 & 2,71 & 2,60 & 2,72 \\
Proprietários & 1,27 & 1,12 & 1,09 & 1,38 & 1,24 & 1,20 \\
Empregados & 1,15 & 1,34 & 1,33 & 1,11 & 1,01 & 1,15 \\
Familiar s/remun. & 0,31 & 0,45 & 0,39 & 0,23 & 0,36 & 0,37 \\
\hline
\end{tabular}

FONTE: IBGE, op. cit. 


\section{Quadro 17 \\ Salários e Retiradas por Região: Média Anual por Pessoa segundo Tipo de Rendi-
mento - em Salário Mínimo de 1985 (inclusive 13ㅇ)}

\begin{tabular}{|c|c|c|c|c|c|c|}
\hline & $\begin{array}{c}\text { TOTAL } \\
\text { M.E. } \\
\text { BRASIL }\end{array}$ & NORTE & NORDESTE & SUDESTE & SUL & CENTRO-OESTE \\
\hline Salário por empregado & 1,02 & 1,15 & 0,85 & 1,08 & 1,10 & 1,00 \\
\hline Ret. por proprietário & 1,78 & 3,36 & 2,38 & 1,50 & 1,64 & 1,74 \\
\hline Ret. por Propr. + & & & & & & \\
\hline $\begin{array}{l}\text { Fam. s/rem. } \\
\text { Lucro + ret. por prop. }\end{array}$ & 1,43 & 2,40 & 1,75 & 1,29 & 1,28 & 1,33 \\
\hline + fam. s/rem. & 3,06 & 4,30 & 3,07 & 2,97 & 3,23 & 2,97 \\
\hline
\end{tabular}

FONTE: IBGE, op. cit.

Nordeste, apresenta valores consideravelmente superiores à média nacional. Mesmo a inclusão dos familiares sem remuneração no divisor não altera essa ordenação. A razão de ambas regiões apresentarem o maior diferencial entre a retirada por proprietário e o salário por empregado deve estar ligada tanto a problemas de índole sóciocultural como à situação de menor desenvolvimento relativo dessas regiões, onde o "efeito rede" das M.E. aparece mais cruamente, possibilitando um maior poder de barganha do proprietário frente a seu empregado. Neste caso, o proprietário do Norte e Nordeste ocupa uma posição mais cômoda na "rede" do que o seu similar das outras regiões do país.

\section{MICROEMPRESAS: ALGUMAS REFLEXÕES}

Em termos de participação no número total de empresas, o peso das microempresas é inquestionável $-77,1 \%$ do total de empresas levantadas pelo Censo 85 , chegando a $90,4 \%$ no caso de serviços. Todavia, não se pode daí derivar uma correlação direta no que se refere à sua efetiva contribuição para o conjunto de atividade econômica (por exemplo, a receita total desse estrato representa apenas $3 \%$ do total de receitas apurado pelos Censos Econômicos - 1985). Em especial a característica de "absorvedoras de mãode-obra", que frequientemente lhes é atribuída e usada como "carro chefe" na argumentação a favor da manutenção e ampliação de medidas de apoio, não pode ser incorporada sem maiores qualificações. A baixa absorção de mão-de-obra que, em média, essas unidades apresentam não as habilita a serem consideradas como absorvedoras "naturais" de mão-de-obra desempregada. Notese que para cada empregado seria necessário, em média, um "microempresário". Portanto, a análise da possível solução do desemprego por essa via implicaria em dividir os desempregados em dois grandes grupos iguais: o primeiro, formado por aqueles que desejariam (e poderiam) ser proprietários e se aventurariam a abrir uma $\mathrm{ME}$; o segundo, daqueles aos quais caberia (ou restaria apenas) o papel de empregado desses "futuros" microempresários.

Observe-se que se as ME representam 77,1 do total de empresas, seu peso (20\%) é bem menos significativo no total de pessoas ocupadas. Enquanto a ocupação média por microempresa é de 2,7 pessoas, para as demais empresas $(22,9 \%)$, que respondem por $80 \%$ do total de pessoal ocupado, a média é de 50 pessoas/empresa. Portanto, pode-se afirmar, a título de ilustração, que, no mínimo, o mesmo número de empregos gerado pelas 1.007 .833 microempresas poderia ser atingido com $54.745(18,5$ vezes a menos) empresas não "micro". Os gráficos "a" e " $b$ " sintetizam esse comportamento desbalanceado entre o número de empresas e sua relevância na composição dos indicadores receita e pessoal ocupado.

O gráfico a permite uma argumentação claramente favorável a medidas do tipo "desburocratizantes", ou mais precisamente, de eliminação da exigência de certos controles legais e/ou fiscais. Afinal, mesmo no caso de um movimento de "sonegação em massa" por parte das microem- 
presas, para o Estado isso representaria apenas a perda da parcela de tributos e impostos que eventualmente tivessem sido gerados por uma receita que corresponde a tão somente $3 \%$ do total de receitas do conjunto de empresas do Censo 85 .

Por outro lado, o gráfico $b$ inequivocamente aponta para a conveniência de os defensores irrestritos de medidas de apoio indiscriminadas às microempresas buscarem argumentos mais sustentáveis que a simples capacidade de absorção de mão-de-obra. E aqui a questão é em relação a quantidade e qualidade do emprego oferecido pelas microempresas. Nesse sentido, deve-se ter presente que se é fato que, para esse segmento de empresas, a noção de "livre mobilidade" ou ausência de barreiras à entrada - é válida, o que facilita sua proliferação, é fato também que os fatores que induzem a esse processo e seus condicionantes são diferenciados, em se tratando de momentos de expansão ou de retração econômica.

A proliferação de microempresas associada a momentos de acentuada crise econômica não pode ser interpretada diretamente de forma positiva ou como "um bom sinal" e nem sempre representa a melhor ou mais racional alternativa. Não raras vezes, a intensa expansão de tal segmento traduz o resultado final das tentativas individuais de "reinserção" na atividade econômica por parte daqueles que foram sendo expulsos pelo movimento de "ajuste" dos demais agentes

\section{GRÁFICO a}

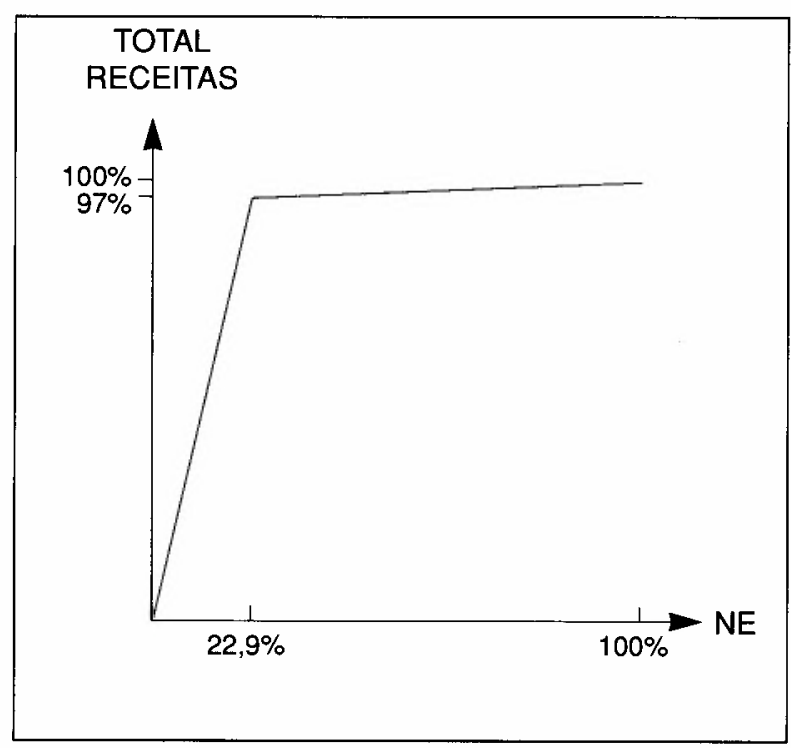

econômicos. É a partir dessa perspectiva que as microempresas podem ser vistas enquanto uma "rede de proteção" a qual impede que parte dos que perderam o emprego (e, em primeiro lugar, saem os pouco ou não qualificados) "caiam" até à categoria de desempregados. Dessa forma é muito mais a manifestação de uma "disfunção" do sistema do que uma alternativa natural de emprego. Apesar de sua aparente limitação, os dados do Censo permitem extrair alguns indicativos disso: a baixa ocupação média; a natureza de atividade - em escala diminuta - exigindo pouco capital inicial, e pouca ou nenhuma qualificação (no comércio e serviços, pequenos bares e restaurantes; na indústria, fabricação de doces caseiros, pequenas confecções etc.); os baixos salários e retiradas; o número de pessoas da família ocupadas sem remuneração; a presença de empresas não oficialmente registradas etc.

A partir desse quadro, a questão que se coloca é: quais são as oportunidades de uma inserção mais positiva dessas empresas enquanto conjunto na estrutura econômica? Tem sentido pensar em incentivar seu crescimento? Em direção a quê e com qual objetivo? Certamente que sua capacidade de absorver mão-de-obra é limitada por suas próprias características. $\mathrm{O}$ proprietário pouco tem a ver com a figura de um empresário capitalista, aproximando-se muito mais do "trabalhador por conta própria". Nessas circunstâncias, que mecanismo iria conduzir ao aumento de

\section{GRÁFICO b}

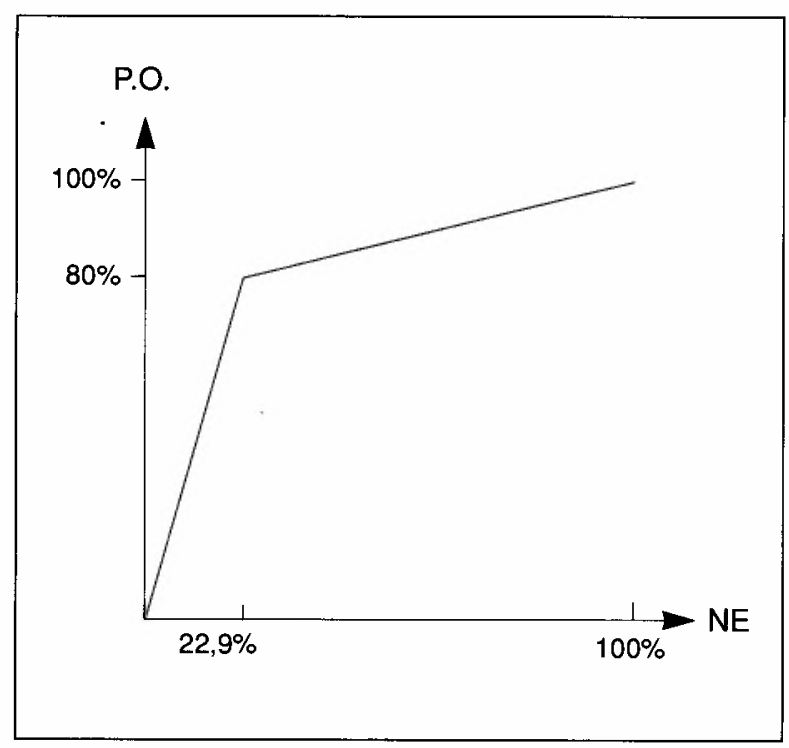


emprego? Incentivar a criação de novas microempresas? O crescimento das já existentes?

Há que se considerar ainda que pouco ou nenhum dinamismo existe nesse setor e que a introdução de técnicas modernas de produção ou de gestão administrativa é praticamente nula. As ME "dinâmicas" (se as há) devem ser em número reduzido e certamente não fazem parte do rol de empresas do volume microempresas do IBGE, dados os critérios de inserção aí adotados (privilegiando o baixo faturamento). Visto isso, julga-se que seria útil uma revisão de tais critérios, passando-se, por exemplo, a incluir como ME empresas com menos de 10 pessoas ocupadas, independente do faturamento. $O$ corte formal e legal pela "pobreza" faz com que ME dinâmicas (poucas pessoas ocupadas, sem divisão formal de tarefas, proprietários que atuam diretamente na produção etc., mas com faturamento acima daquele definido legalmente) fiquem fora da categoria $\mathrm{ME}$ e, talvez, fossem exatamente estas as que possibilitariam um maior retorno econômico e social (receita, emprego etc.) às chamadas medidas de incentivos às ME.

Defende-se aqui, portanto, uma reflexão no sentido de superar-se a concepção de medidas de apoio - em especial no que tange a subsídios governamentais - genéricas e indiscriminadas às ME. Essas são, de maneira geral, unidades de reduzido (ou nulo) poder de mercado em relação a seus fornecedores e clientes. A causa desse débil poder de negociação encontra-se em fatores tais como o grande número de empresas concorrendo nos mesmos mercados; o seu reduzido porte; o fato de serem produtoras de produtos (e serviços) não diferenciáveis e a constante utilização da redução de preço como arma competitiva principal. Uma das manifestações mais claras desta fragilidade é a redução da remuneração dos proprietários das ME a níveis mínimos, compatíveis unicamente com a sua manutenção como agente econômico "independente". Portanto, é muito provável que qualquer subsídio ou vantagem financeira oferecidos pelo governo a essas empresas acabem sendo apropriadas pelos agentes de maior poder de mercado com os quais essas unidades se relacionam ${ }^{12}$.

Sendo assim, uma política de subsídios deve levar em conta esses condicionantes e ser claramente delimitada quanto à sua abrangência, objetivos e implicações, em termos econômicos e sociais. Talvez a política mais "sábia" seja a de não subsidiar esses empreendimentos, simplificando, por outro lado, o máximo possível todos os requisitos legais para a sua abertura e funcionamento, deixando que o próprio mercado encontre as condições que permitam ou não a reprodução desse tipo de empresas.

Por outro lado podem ser pensadas políticas de apoio ou promoção mais eficazes, que inclusive possam vir a aumentar o poder de mercado destas empresas, com resultados benéficos no longo prazo sobre a remuneração do proprietário (e talvez indiretamente sobre a dos empregados). Tais políticas deveriam contemplar o desenvolvimento de programas de assistência tecnológica para ramos de atividades selecionados, de forma a possibilitar o acesso das ME a tecnologias mais modernas, no que tange a produto, processo e gestão. Nesse caso, o oferecimento de linhas de crédito de longo prazo para financiar a implementação de programas de melhoria e desenvolvimento tecnológico encontraria maiores justificativas, pois é de se esperar que a incorporação de tecnologia por uma ME a coloque em condições diferenciadas frente a suas concorrentes, impedindo, simultaneamente, a apropriação do diferencial de produtividade pelọs outros agentes de maior poder de mercado com que a unidade transaciona. Deve ficar claro que o resultado de uma política desse tipo será, no médio prazo, a de possibilitar a empresa beneficiada pelo programa o deslocamento da categoria microempresa para a de pequena empresa.

ABSTRACT: This paper aims at analyzing the recently published 1985 Census of Small Firms data (entreprises with total receipts amounting to less than US\$ 40.000 in 1985). Over all profile and performance, as well as characteristics of small firms from different branches of activity and size groups are the focus of the analysis. An attempt is made to describe the profile of the "average small firm" in Brazil.

KEY TERMS: Small firms, performance, branches of activity, "average small firm".

12. A esse respeito ver PORTER, M. Estratégia Competitiva. (Trad. port.) Rio de Janeiro, Ed. Campus, 1986, cap. 1 e 6. 